\title{
Environmentally sustainable sand mining based on GIS based sediment yield estimation
}

\author{
SHRIKANT OJHA AND SANGEETA CHOUDHARY
}

\begin{abstract}
Rampant urbanization, which happens to be the major cause for sand demand is responsible for unsustainable extraction of sand from dried and sometimes even wet river beds. Demand for sand from construction sector in India is expected to grow from 630 million tonne in 2014 to 1.4 billion tonne in 2020 (material usage report). Out of different sources like, river sand, ocean sand, dessert sand, manufactured sand, the river sand is most preferred because of mineralogical properties and grain structure, easy local availability and low cost. This has led to rampant, regulated and unregulated, sand mining in most of the reservoirs and river beds. Though removal of sand/sediments from riverbeds and reservoir beds is essential to prevent shallowing and consequent widening of river bed and reduction of capacity of reservoir. In absence of yield estimation models sand mining leases are allotted where amount of sand mined is decided as $3 \mathrm{~m}$ from river or $1 \mathrm{~m}$ above water table, whichever is less. This may not be environmentally sustainable and may lead of medium to long term changes in riverbed profile and consequent negative environmental impact.
\end{abstract}

KEY WORDS : Environmentally, Sustainable, Sand mining based, GIS

How to cite this Article : Ojha, Shrikant and Choudhary, Sangeeta (2017). Environmentally sustainable sand mining based on GIS based sediment yield estimation. Engg. \& Tech. in India, 8 (1\&2) : 49-57; DOI : 10.15740/HAS/ETI/8.1\&2/ 49-57. 